Available online at GSC Online Press Directory

GSC Biological and Pharmaceutical Sciences

e-ISSN: 2581-3250, CODEN (USA): GBPSC2

Journal homepage: https://www.gsconlinepress.com/journals/gscbps

(RESEARCH ARTICLE)

\title{
Hepatoprotective effect of Tetracarpidium conophorum oil in diclofenac sodium induced hepatotoxicity in rats
}

\author{
Ezealisiji Kenneth Maduabuchi ${ }^{1, *}$ and Mbah Chika John ${ }^{2}$ \\ ${ }^{1}$ Department of Pharmaceutical Chemistry, Faculty of Pharmaceutical Sciences, University of Port Harcourt, Port \\ Harcourt, Nigeria. \\ ${ }^{2}$ Department of Pharmaceutical and Medicinal Chemistry, Faculty of Pharmaceutical sciences, University of Nigeria, \\ Nsukka, Nigeria.
}

Publication history: Received on 02 February 2019; revised on 18 February 2019; accepted on 21 February 2019

Article DOI: https://doi.org/10.30574/gscbps.2019.6.2.0018

\begin{abstract}
Western dietary lifestyle has gained lots of attention globally with high level of patronage hence generating human health concern. This calls for dietary balance and supplementation with vegetables, fish and nuts which are known to contain Omega-3, Omega-6 and Omega-9 fatty acids. Plant based oils such as Walnut (Tetracarpidium conophorum), are known to be rich in Omega-fatty acids, which can help lower pathological conditions such as heart diseases. Therefore, the study investigated the effects of pre-treatment with Tetracarpidium conophorum oil (Oil of African Walnut) in adult male Wistar rats exposed to diclofenac sodium (DFS). Twenty four male rats were randomly divided into four groups of six rats each, this includes: Group 1-Normal control; Group 2- DFS control; Group 3- low dose Tc oil + DFS; and Group 4- high dose Tc oil + DFS. The rats in group 2 received intramuscular dose of DFS (10 mg/kg body weight/day during the last 7 days of T. conophorum oil treatment. Rats in treatment groups 3 and 4 were pre-treated with T. Conophorum oil at 5.0 and $10 \mathrm{ml} / \mathrm{kg} \mathrm{b.w/day} \mathrm{per} \mathrm{oral} \mathrm{for} 21$ days, afterwards they were administered DFS at $10 \mathrm{mg} / \mathrm{kg}$ b.w/day respectively for 7 days. The result showed that, DFS increased significantly biochemical and pro-inflammatory markers. Pre-treatment with oil of $T$. conophrum significantly prevented the pathological conditions due to diclofenac. In conclusion, pre-treatment dosing with oil of T. Conophorum could be suggested as a novel adjuvant in long term management of rheumatoid arthritis in man using diclofenac sodium.
\end{abstract}

Keywords: Omega-3; Tetracarpidium conophorum; Diclofenac sodium; Rheumatoid arthritis; Omega-9; Histological

\section{Introduction}

Diclofenac sodium is a benzene acetic acid derivative and non-steroidal anti-inflammatory drug (NSAID) with analgesic, anti-inflammatory and antipyretic property. Diclofenac sodium is known to block the conversion of arachidonic acid into prostaglandin precursors via a non-selective reversible inhibition of cyclooxigenase (COX). This subsequently leads to inhibition of prostaglandins that are implicated in pain, fever and inflammation. Diclofenac is widely used as a pain killer though it still has some notable adverse effects. An immune-allergic component [1] and allergic variants of Cytochrome-P 2CB [2] are all involved in diclofenac induced liver injury, also mitochondrial injury [3], generation of oxidative stress and change in protein integrity [4] all points towards possible route of hepatocyte damage [5]. Hence the need for natural therapeutic agent that can prevent or reverse an already existing pathological conditions caused by chronic use of diclofenac in the management of disease conditions such as chronic arthritis, rheumatism and other life threatening related esteomyelities. In previous report by Ezealisiji et.al, oil of T. Conophorum has been found to possess anti-ulceroginic effect [6]. Also, chemometric profiling of N-Hexane extract of T. conophorum has revealed the presence of Omega fatty acids and oleic acids [7]. Omega-3 fatty acids have been noted to have non-steroidal anti-

\footnotetext{
${ }^{*}$ Corresponding author

E-mail address: Kenneth.ezealisiji@uniport.edu.ng
} 
inflammatory drug sparing effect [8]. Omega-3 and Omega-6 fatty acids exist in high ratio as found in western diets (45:1) against 2:1 for local diets rich in vegetables and nuts. Presence of intolerable high content of Omega-6 polyunsaturated fatty acids in western diets has been implicated in a number of life threatening disease conditions such as heart disease, osteoarthritis, and rheumatoid arthritis. This calls for a balance through the use of foods (Organics) rich in Omega-3 fatty acids. Hence present study investigated the effect of pre-treatment with T. Conophorum oil on biochemical hepatic bio-markers and haematological indices in diclofenac-induced hepatotoxicity in male Wistar rats.

\section{Material and methods}

\subsection{Chemicals}

Diclofenac sodium $(75 \mathrm{mg} / 3 \mathrm{ml}$ ) was purchased from Baratha Pharmaceuticals Limited, Port Harcourt, Nigeria. NHexane and distilled water were purchased from Sigma Aldrich (St. Lois, MO, USA). Every other chemical used were of analytical grade and were used as such without further purification.

\subsection{Plant material and extraction of oil}

The cooked African walnut (T. Conophorum) was purchased from a local market in Choba, Port Harcourt, and Nigeria. The nuts were identified and authenticated by Dr. Ekeke of Plant Biotechnology Unit of University of Port Harcourt, Nigeria. A voucher specimen UPHPB/1085/2018 of the sample was deposited in the departmental herbarium for further use. Cooked T. Conophorum nuts were ground into powder using a Willey mill (Thomas Willy Mills, Swedesboro, NJ, USA). Six hundred grams of the pulverised powder was extracted with n-hexane (1 litre) for $48 \mathrm{~h}$. The resultant oil extract was collected and stored in a refrigerator $\left(-14^{\circ} \mathrm{C}\right)$ till further use.

\subsection{Animal care}

Male Wister rats (twenty four) weighing 200-250 g obtained from the Animal House of the Department of Pharmacology, University of Port Harcourt, were used for present study. They were fed with standard rodent feed (Intergrated Livestock feeds Limited, Aba, Nigeria). The rats were allowed free access to table water ad libitum. The animals were housed in an animal room maintained at $24.4 \pm 1^{\circ} \mathrm{C}$ and $50.6 \pm 6 \%$ relative humidity with an alternating 12:12-hour light-dark cycle. All animal procedures were reviewed and approved by the local institutional use of animal Ethics Committee of the University of Port Harcourt, Nigeria.

\subsection{Experimental design}

The rats were randomly divided into four groups of six rats each, this include: Group 1-Normal control; Group 2- DFS control; Group 3- low dose T. c oil + DFS; and Group 4- high dose T. c oil + DFS. The rats in group 2 received intramuscular dose of DFS $(10 \mathrm{mg} / \mathrm{kg}$ body weight/day during the last 7 days of T. conophorum oil treatment. Rats in treatment groups 3 and 4 were pre-treated with T. Conophorum oil at 5.0 and $10 \mathrm{ml} / \mathrm{kg} \mathrm{b.w/day} \mathrm{per} \mathrm{oral} \mathrm{for} 21$ days, afterwards they were administered DFS at $10 \mathrm{mg} / \mathrm{kg}$ b.w/day respectively for 7 days.

\subsection{Biochemical and haematological investigation}

At the end of 28 days, the animals were sacrificed (euthanasia) and blood sample collected by cardiac puncture into heparinised tubes, centrifuged and plasma samples taken for analysis. Blood samples needed for haematological investigation was collected in ethylenediamine tetraacetic acid (EDTA) sample bottles. Hematological parameters such as full blood count (FBC), haemoglobin, (Hb), packed cell volume (PCV) and Total and differential white blood cell counts (WBC) were analyzed. The haemocytometer was used for haematological analysis and total leukocyte count [9-10]. The hepatic tissues were also harvested for histopathological investigation. The analytical kits for determination of hepatic biochemical markers were purchased from Jochem Pharmaceutical and Chemical Company Ltd, Choba, Port Harcourt. The analysis was carried out according to the manufacturer's instruction manual.

\subsection{Histopathological analysis}

The hepatic tissues were fixed in $10 \%$ formalin immediately after harvesting. It was dehydrated in ethanol, purified in Xylene and subsequently embedded in paraffin wax. A microtome was used to cut the tissue into $0.05-0.15 \mu \mathrm{m}$ sections, fixed on glass slides and further stained with haematoxylin-eosin (H\&E). Slide examination was done under light microscope at x 40 magnification as photomicrographs were taken with a Toshiba digital camera [11-12]. 


\subsection{Statistical analysis}

The results are expressed as mean \pm SEM of triplicate determinations $(n=3)$. Statistical comparisons were performed by one-way analysis of variance using Graphical Prism 5 software followed by Dunnett`s post hoc least significant (LSD) test. Comparing with control group, $\mathrm{p}<0.05$ was considered to be significantly different.

\section{Results}

\subsection{Effect of $T$. conophorum on alanine aminotransferase (ALT), aspartate aminotransferase (AST), alkaline phosphatase (ALP), total bilirubin (TB) and Uric acid in diclofenac sodium (DFS) - induced hepatotoxicity in rats}

Result showed significant $(\mathrm{P}<0.05)$ increase in ALT enzyme activity in group 2, 3 and 4 (DFS control, low dose T. c oil + DFS, and high dose T. c oil + DFS) compared to normal control group (Table 1). Significant decrease in ALT enzyme activity were observed in group 3 (low dose T. c oil + DFS) and group 4 (high dose T. c oil + DFS) when compared to DFS control group alone. The AST enzyme activity showed a significant $(\mathrm{P}<0.05)$ increase in group 2 (DFS control, group 3 (low dose T. c oil + DFS) and group 4 (high dose T. c oil + DFS) compared to normal control group, (Table 1). There were significant lowering in AST activity in group 3 (low dose T. c oil + DFS) and group 4 (high dose T. c oil + DFS) relative to DFS control group. Also compared to group 3, a significant reduction was noted in group 4 (AST activity). There were no significant difference in the ALP activity in both control group though relative to the activity in group 3 (low dose T. c oil + DFS) and 4 (high dose T. c oil +DFS) the enzyme activities were significantly reduced when compared to both control groups. The Uric acid level in the two test groups 3 (low dose T. c oil + DFS) and group 4 (high dose T. c oil + DFS) were observed to be significantly increased when compared to both control groups. The DFS control group showed a higher Uric acid level when compared to the normal control group. Relative to the DFS control group, there were significant increase in Total Bilirubin (TB) in group 3 and 4, though the TB in all groups 2, 3, and 4 showed higher value when compared to the normal control group.

Table 1 Effect of T. conophorum oil on alanine aminotransferase (ALT), aspartate aminotransferase (AST), alkaline phosphatase (ALP), total bilirubin (TB) and Uric acid in diclofenac sodium (DFS) - induced hepatotoxicity in rats

\begin{tabular}{cllllll}
\hline Sr. No. & Groups & ALT $(\boldsymbol{\mu} / \mathbf{L})$ & AST $(\boldsymbol{\mu} / \mathbf{L})$ & ALP $(\boldsymbol{\mu} / \mathbf{L})$ & TB $(\mathbf{m g} / \mathbf{d l})$ & UA $(\mathbf{m g} / \mathbf{d l})$ \\
\hline 1 & Normal control & $12.00 \pm 0.46$ & $49.00 \pm 0.08$ & $83.00 \pm 0.02$ & $12.00 \pm 0.08$ & $280.00 \pm 2.02$ \\
2 & DFS control & $22.00 \pm 0.52$ & $81.00 \pm 2.02$ & $80.00 \pm 2.00$ & $22.00 \pm 2.04$ & $320.00 \pm 6.01$ \\
3 & Low dose T. c oil + DFS & $16.00 \pm 2.04$ & $72.00 \pm 0.01$ & $76.00 \pm 1.08$ & $20.00 \pm 0.02$ & $420.00 \pm 4.02^{*}$ \\
4 & High dose T. c oil + DFS & $14.00 \pm 2.08^{*}$ & $59.00 \pm 0.46^{*}$ & $72.00 \pm 2.02$ & $15.00 \pm 0.09^{*}$ & $360.00 \pm 2.01^{*}$ \\
\hline
\end{tabular}

\subsection{Effects of T. conophorum oil pre-treatment on the hematological parameters of rats with diclofenac sodium (DFS)-induced hepatotoxicity}

The administration of diclofenac sodium $10 \mathrm{mg} / \mathrm{kg}$ body weight/day (Group 2- DFS control), slightly affected the RBC, WBC, Platelet count and haemoglobin concentration, as well as basophils, PVC and lymphocytes percentages, when compared to normal control. However there was significant $(\mathrm{p}<0.05)$ increase in the concentration of neutrophils in diclofenac-treated rats and those of rats pre-treated with low and high doses of T. conophorum oils $(5.0$ and $10.0 \mathrm{ml} / \mathrm{kg}$ b.w/day respectively for 7 days. Concentration of Eosinophils was significantly $(\mathrm{p}<0.05)$ reduced in both DFS and $T$. conophorum oil pre-treated groups (Table 2). With respect to normal control group, there was a slight increase in platelet count in DFS control group, on the contrary, a significant $(\mathrm{p}<0.05)$ increase was recorded in group 3 and 4 (Low dose Tc oil + DFS) and (High dose Tc oil +DFS) respectively. The Lymphocyte count was not significantly affected in both the diclofenac control group and all other T. conophorum oil pretreated groups (groups 3 and 4). Significant reduction in monocyte count was observed in diclofenac control group (group 2) and T. conophorum oil pretreated groups. Relative to normal control group, DFS, and T. conophorum oil pretreated groups (groups 3 and 4), showed a significant reduction in total WBC count. 
Table 2 Effects of T. conophorum oil pre-treatment on the hematological parameters of rats with diclofenac sodium (DFS) induced hepatotoxicity

\begin{tabular}{|c|c|c|c|c|c|c|c|c|c|}
\hline $\begin{array}{l}\text { Treatment } \\
\text { Dose }(\mathrm{mg} / \mathrm{kg})\end{array}$ & $\begin{array}{l}\text { RBC } \\
\left(\times 10^{12} / 1\right)\end{array}$ & $\begin{array}{l}\text { PCV } \\
(\%)\end{array}$ & $\begin{array}{l}\mathrm{Hb} \\
(\mathrm{g} / \mathrm{dl})\end{array}$ & $\begin{array}{l}\text { WBC } \\
\left(\times 10^{9} / \mathbf{l}\right)\end{array}$ & $\begin{array}{l}\text { NEUT } \\
(\%)\end{array}$ & $\begin{array}{l}\text { LYMP } \\
(\%)\end{array}$ & $\begin{array}{l}\text { MONO } \\
(\%)\end{array}$ & $\begin{array}{l}\text { EASIN } \\
(\%)\end{array}$ & $\begin{array}{l}\text { PLAT } \\
(\%)\end{array}$ \\
\hline Normal control & $5.00 \pm 0.15$ & $48.0 \pm 3.2$ & $18.0 \pm 1.0$ & $6.20 \pm 0.8$ & $52.0 \pm 2.0$ & $50.2 \pm 0.9$ & $9.20 \pm 0.4$ & $4.82 \pm 0.8$ & $150.5 \pm 8.0$ \\
\hline DFS control & $4.50 \pm 0.12$ & $47.0 \pm 4.1$ & $18.0 \pm 1.0$ & $6.30 \pm 1.0$ & $59.0 \pm 1.0$ & $48.0 \pm 01$ & $7.40 \pm 0.8$ & $3.20 \pm 0.1$ & $156.8 \pm 12.0$ \\
\hline $\begin{array}{l}\text { Low dose } \\
\text { T. c oil + DFS }\end{array}$ & $5.30 \pm 0.13$ & $59.0 \pm 11$ & $20.2 \pm 3.0$ & $5.50 \pm 2.0$ & $63.0 \pm 2.0$ & $52.4 \pm 0.8$ & $7.30 \pm 0.1$ & $3.50 \pm 0.4$ & $168.2 \pm 14.0^{*}$ \\
\hline $\begin{array}{l}\text { High dose T. c oil + } \\
\text { DFS }\end{array}$ & $5.90 \pm 0.45$ & $58.0 \pm 09 *$ & $24.2 \pm 2.0$ & $5.90 \pm 0.8$ & $65.0 \pm 4.0 *$ & $50.1 \pm 2.0$ & $7.80 \pm 0.8$ & $3.70 \pm 1.0$ & $220.4 \pm 4.0 *$ \\
\hline
\end{tabular}

Data were expressed as mean SEM, Significant at $\mathrm{p}<0.05$ when compared to control and $\mathrm{p}<0.05$ when compared to DFS control.

\subsection{Histopathology}
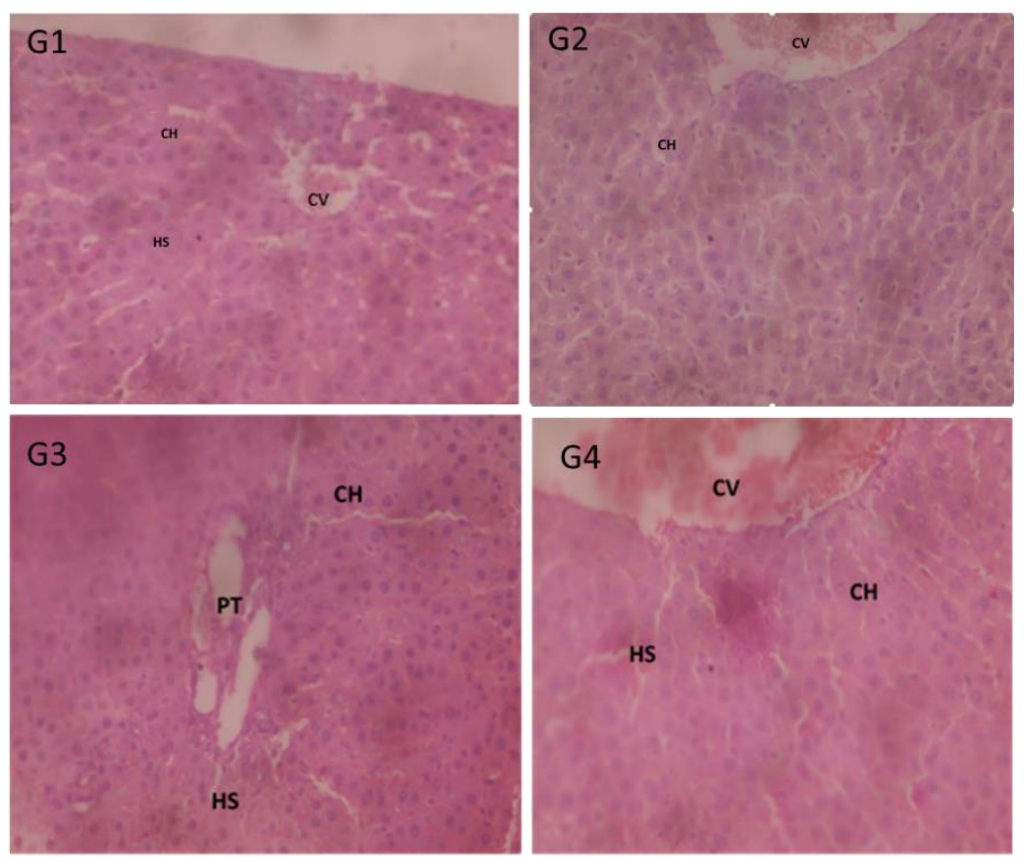

Figure 1 Light micrograph of hepatocytes from groups 1- 4 (G1, G2, G3 and G4). CV- Central vein, CH-Cords of hepatocytes and HS-Hepatic sinusoids

In group 1 (fig 1), we have congested central vein (meaning the vein is filled with blood). This does not necessarily indicate any pathology as blood will naturally pool in the veins if the heart stops pumping blood (when the animal dies). Cords of hepatocytes were seen radiating from the central vein and were not distorted hence indicating a histological normal tissue. Also there are no inflammatory cells present. Histopathological findings in group 2 show that the central vein is also congested but is not a direct indicator of an underlying pathology. The cords hepatocytes radiating away from the central vein are also not distorted. However, there are increased inflammatory cells in the sinusoids (distributaries from the central vein) which indicate an underlying pathology. This is consistent with the expected result, as Diclofenac (which is hepatotoxic) was administered to this group. In group 3, micrograph above captured the portal triad and no distortion was observed. Also the cords of hepatocytes are not distorted and there are no significant inflammatory cells in the sinusoids. This denotes a histological normal tissue and shows the hepatoprotective effect of the oil. (Low dose Tc oil). However, in group 4, the central vein in this group is also congested but this is not a significant indicator of hepatotoxicity. Normal cords of hepatocytes were also observed indicating prevention of diclofenac induced liver damage. This is consistent with expected result as higher dose of Tc oil was administered to this group. Also there are no significant levels of inflammatory cells in the sinusoids. 


\section{Discussion}

Present research findings shows that the administration of diclofenac sodium produced an observed distortion in the antioxidant system and pro-inflammatory responses with a significant increase in the systemic activities of ALT and AST. However, pre-treatment with low and high doses of T. Conophorum oil prior to diclofenac sodium treatment reversed the progression of physiological abnormalities. The observed pharmacological benefit was dose dependent. Pre-treatment with T. conophorum oil was observed to boost the antioxidant system hence increased its potential in handling treats posed by further exposure to diclofenac sodium which is an oxidative aggravating agent. Elevation of WBC count, Platelets, Lymphocytes and Neutrophil/Lymphocyte ratio as well as Uric acid level are considered useful parameters of systemic inflammatory activities [13-15]. Increased systemic levels of Uric acid are known to promote inflammatory pathways by activating some protein kinase enzyme system. The increase in UA level in DFS treated group (group 2) was linked with compromised cellular aptosis, this justified the observed increase in total WBC in diclofenac sodium treated group (DFS control group). However, all the T. conophorum oil pre-treated groups showed plasma levels of haematological and Biochemical biomarkers comparable to those in physiological condition.

\section{Conclusion}

The haematological and Biochemical results were complimentary with the histological findings. Diclofenac sodium was found to distort the physiological hepatic architecture. The research hence concludes that the pre-treatment of lower animals with oil of T. Conophorum prior to diclofenac sodium treatment will offer a promising level of hepato-protection.

\section{Compliance with ethical standards}

\section{Acknowledgments}

The authors are thankful to Head of Department and all members of the Pharmacology Department of Faculty of Pharmaceutical Sciences, University of Port Harcourt, Nigeria for their help in using the animals and apparatus necessary for the pharmacological study.

\section{Disclosure of conflict of interest}

The authors report no conflicts of interest.

\section{Statement of ethical approval}

All animal study protocol was carried out in accordance with the guidelines of the Committee on Care and Use of Experimental Animals and Environmental Ethics, University of Port Harcourt.

\section{References}

[1] Andrea H, Roland L, Robert G, Michaela B, Thomas H, Werner A, Lothar V, Walther S, Fatima F, and Martin H. (2010). Diclofenac hypersensitivity: Antibody responses to the parent drug and relevant metabolites. PLoS One, 5(10), e13707.

[2] Ngui JS, Tang W, Stearns RA, Shou M, Miller RR, Zhang Y, Lin JH and Baillie TA. (2000). Cytochrome P450 3A4mediated interaction of diclofenac and quinidine. Drug Metabolism and Disposition, 28(9), 1043-50.

[3] Rajeshwary G, Sumanta KG, Luis Felipe BBF, Bruce H and Aldrin VG. (2016). Diclofenac induces proteasome and mitochondrial dysfunction in murine cardiomyocytes and hearts. International Journal of Cardiology, 223(1), 923-935.

[4] Haritha C, Reddy A, Gopala YA, Kalakumar B and Reddy GD. (2010). Oxidative stress induced by diclofenac alone and under the influence of certain variables in broilers. Toxicology International, 17(1), 27-29.

[5] Fernando B. (2010). Non-steroidal anti-inflammatory drugs: What is the actual risk of liver damage? World Journal of Gastroenterology, 16(45), 5651-5661.

[6] Kenneth ME and Emmanuel AN. (2015). Investigation of anti-ulcerogenic properties of fixed oil of African walnut (Tetracapidium conophorum) against gastric ulcers in albino wistar rats. Nigerian Journal of Pharmaceutical and Applied Science Research, 4(2), 7-11. 
[7] Ezealisiji KM and Agbo MO. (2016). Phytochemical analysis of N-Hexane nut extract of Tetracarpidium conophorum (Euphorbiaceae) using ultraviolet-visible, fourier transform infrared and gas chromatography mass spectrometry techniques. Journal of Pharmacognosy and Phytochemistry, 5(6), 332-336.

[8] Galarraga B, Ho M, Youssef HM, Hill A, McMahon H, Hall C, Ogston S, Nuki G and Belch JJ. (2008). Cod liver oil (n3 fatty acids) as an non-steroidal anti-inflammatory drug sparing agent in rheumatoid arthritis. Rheumatology (Oxford); 47(5), 665-9.

[9] Freund M and Carol B. (1064). Factors affecting haemocytometer counts of sperm concentration in human semen. Journal of Reproduction and Fertility, 8(1), 149-155.

[10] Lars KN, Gordon KS and Paul FG. (1991). Hemacytometer cell count distributions: Implications of non-poisson behavior. Biotechnology Progress, 7(1), 560-563.

[11] Shaima MA, Amr KE, Hala EH. (2016). Ultrastructure and histomorphometric analysis of human umbilical cord vessels in preeclampsia: a potential role of VEGF, VEGFR-1 and VEGFR-2. Romanian Journal of Morphology and Embryology, 57(2), 681-689.

[12] Wade LS, John GH, Karl H, and Henry MR. (2015). VarBase: A platform for the storage and clinical interpretation of next generation sequencing data. Journal of Pathology Informatics, 6, 24-32.

[13] Gaafar R, Mohsen E, and Thomas B. (2017). Gout: An old disease in new perspective - A review. Journal of Advanced Research, 8(5), 495-511.

[14] Changyi C, Jian-Ming L and Qizhi Y. (2016). Hyperuricemia-Related Diseases and Xanthine Oxidoreductase (XOR) Inhibitors: An Overview. Medical Science Monitor, 22, 2501-2512.

[15] Xiaoni S, Wenjie L, Fabao G, Dandan L, Jing H, Yan L, Zeping Z, Hui J, Yinglan Z and Xiaobo C. (2016). Uric acid induces cognitive dysfunction through hippocampal inflammation in rodents and humans. Journal of Neuroscience, 36 (43), 10990-11005.

\section{How to cite this article}

Ezealisiji KM and Mbah CJ. (2019). Hepatoprotective effect of Tetracarpidium conophorum oil in diclofenac sodium induced hepatotoxicity in rats. GSC Biological and Pharmaceutical Sciences, 6(2), 84-89. 